\title{
Use of Internet Health Information Among Students in Jeddah, Saudi Arabia: A Cross-Sectional Study
}

\author{
Etab S. Alghamdi ${ }^{1}$, Alaa S. Alqarni ${ }^{1}$, Maryah M. Bakarman ${ }^{2}$, Abdel Moniem Mukhtar ${ }^{3}$ \& Marwan A. Bakarman ${ }^{3}$ \\ ${ }^{1}$ Food and Nutrition Department, Faculty of Home Economics, King Abdul-Aziz University, Jeddah, Saudi \\ Arabia \\ ${ }^{2}$ Communication Theory and Methodology Department, College of Liberal Arts and Social Sciences, Cleveland \\ State University, Cleveland, Ohio, United States \\ ${ }^{3}$ Family and Community Medicine Department, Rabigh Faculty of Medicine, King Abdul-Aziz University, \\ Jeddah, Saudi Arabia
}

Correspondence: Dr. Etab Saleh Alghamdi. Food and Nutrition Department, Faculty of Home Economics, King Abdul-Aziz Univ., Jeddah, Saudi Arabia. E-mail: asalghamdy2@kau.edu.sa

Received: February 18, 2019 Accepted: March 18, 2019 Online Published: April 3, 2019

doi:10.5539/gjhs.v11n5p51 URL: https://oi.org/10.5539/gjhs.v11n5p51

\begin{abstract}
Background: Internet is a resource used to deliver health information, and has the potential to provide nutrition education in particular for individuals with a good level of education. The purpose of this study was to investigate the use of internet as a source for health information and analyzing the related factors for internet as a source for health information among students in Jeddah, Saudi Arabia.
\end{abstract}

Methods: We recruited 164 high schools, undergraduate and postgraduate students living in Jeddah, Saudi Arabia. A self-administered structured questionnaire to collect data on searching the internet for health information was used. It included frequency and timing of search, type of information, use of information in decision making, general health condition and socio-demographic characteristics. Differences between students who perceived and those who did not perceive improvement in health care after using internet health information were assessed using the chi-squared test.

Results: $92.7 \%$ of the students usually searched the internet for health information and $84.8 \%$ perceived internet health information as a help towards improving their health status. Students at higher educational levels talked significantly more often with their doctors regarding the health information they got from the internet $(p=0.014)$. We found significantly higher rates of perceived improvement in health among females $(p<0.001)$, participants who trusted the health information they got from the internet $(p<0.001)$, those who searched the internet for health information for themselves and other persons $(\mathrm{p}=0.034)$, who searched for information on health care, physical fitness and nutrition and specific diseases $(p=0.005)$ and those who did it to increase their knowledge $(p=0.024)$.

Conclusion and Recommendations: The majority of participants perceived the health information they got from the internet as a help towards improving their health status. Interventions should be developed to enhance the use of internet health information among males and high school students.

Keywords: internet, health information, health care, nutrition education

Key Message: Internet is widely used as a source for health information among Saudi students

\section{Introduction}

Today's culture enhances patients and healthy individuals to play an active role in taking care of their health. Most young adults are able to search electronic sources for health information and to use these for decision making (Stellefson et al., 2011; Stellefeson et al., 2012; Britt et al., 2017; Bakarman, 2017), and internet is becoming a major source of health information for the new generation (Tao, 2017). Several studies examined students' online habits and their use of internet as a source for health information (Osei Asibey, Agyemang, \& Boakye Dankwah, 2017; Albarrak et al., 2016; O'Carroll, 2015; Aldebasi \& Ahmed, 2013; Schwartz, 2016; Horgan \& Sweeney, 2012; Percheski, 2011; Bensley et al., 2014). A cross-sectional study conducted in 3 universities in Ghana and included 650 students (Osei Asibey, Agyemang, \& Boakye Dankwah, 2017), reported that $67.7 \%$ of the students used the 
internet for health purposes. Most of the students (72.4\%) used internet health information to assist in modifying their lifestyle and only $39.5 \%$ used it for discussions with their health professionals. $73.6 \%$ of the students reported a 'lot to somehow' improvement in health after using internet health information (Osei Asibey, 2017). A cross-sectional study which was conducted among 448 college students in Riyadh, Saudi Arabia, found that half of the students used internet to search for health information on obesity and more than a half used this information to modify their lifestyle (Albarak, 2016). Female students used internet health information to modify their lifestyle significantly more than male students (Albarak, 2016). A web-based survey of 213 medical students in Halifax, Canada, showed that most of the participants used Google on a daily basis and that Wikipedia and UpToDate were also commonly used (O'Carroll, 2015). A study conducted in four medical colleges in Qassim University, Saudi Arabia, enrolled 500 students (Aldebasi \& Ahmed, 2013). While internet was the most preferred source of medical information in males (84\%), it was used for this purpose in only $14 \%$ of the females. Whereas most of the male students (54\%) accessed internet at cyber cafés, the majority of female students used it at home (84\%) (Aldebasi \& Ahmed, 2013). Horgan and colleagues investigated internet habits of 922 university students aged 18-24 years in Ireland (Horgan \& Sweeney, 2012). $72.4 \%$ used the internet several times per day and $66.1 \%$ used it to search for health information. They used the internet to search for health information on specific diseases $(7.1 \%, \mathrm{n}=37)$, signs and symptoms $(11.6 \%, \mathrm{n}=60)$, treatment options $(4.4 \%, \mathrm{n}=23)$, causes of the diseases $(1.5 \%, \mathrm{n}=8)$, prescription medication $(6.2 \%, \mathrm{n}=32)$ and alternative treatments $(3.5 \%, \mathrm{n}=18)$ (Horgan \& Sweeney, 2012). A further study of 1,060 first-year university students at the Midwest of USA showed that $78 \%$ of the students used the internet to search for health information (Percheski \& Hargittai, 2011). They found that female students used internet health information significantly more often than male students. Non-native English speakers, students with greater Web skills and students living away from their parents showed significantly higher likelihood to use internet health information (Percheski \& Hargittai, 2011).

The aim of our study was to investigate the use of internet as a source for health information and analyzing the related factors for internet as a source for health information among students in Jeddah, Saudi Arabia.

\section{Methods}

We followed the 'Strengthening the Reporting of Observational Studies in Epidemiology' (STROBE) guidelines for reporting our study methods and results (von Elm, 2007).

Study design: A cross-sectional study was conducted between September 2017 and February 2018.

Study participants: We recruited 164 high school students, undergraduate and postgraduate students living in Jeddah, Saudi Arabia. Students $\geq 16$ years old were eligible to participate. University students were recruited from King Abdulaziz University in Jeddah. We used flyers and social media to invite students to participate in the study. Excluded from the study were students who suffered from health problems that affect their ability to use internet.

Study setting and location: The study was conducted in Jeddah city, a coastal city on the Red Sea on the western region of Saudi Arabia.

Data collection method and study variables: We used a self-administered structured questionnaire that was developed and used by Power and colleagues (Power, 2017). After taking permission from the authors, we modified the questionnaire and customized it to the Saudi culture. The questionnaire contained questions on age, sex, educational level, searching the internet for health information, number of searched websites, trustworthiness and usefulness of internet health information, type of internet health information, use of information in decision making, general health conditions.

Sample size: Our primary expected outcome was the role of internet health information in improving health. We anticipated that $88 \%$ of our study participants will find internet health information as a help for improving health. Assuming this rate of perceived improvement in health in our study, we needed to recruit a minimum of 162 students to estimate improvement in health care with a precision of $5 \%$. We succeeded to recruit a slightly higher number of eligible students in our study sample $(n=164)$.

Statistical analysis: We used frequencies and absolute numbers to describe categorical variables and mean and standard deviation to describe continuous variables. Differences between students who perceived and who did not perceive improvement in health care after using internet health information were assessed using the chi-squared test. A p value less than 0.05 was considered significant. SPSS version 21.0 was used to conduct all statistical analyses.

Ethical considerations: The study protocol was reviewed and approved by the Biomedical Research Ethics Unit at King Abdulaziz University. Participation was voluntary, data confidentiality was assured and informed consent was obtained from all participants. 


\section{Results}

Our study included 164 participants, $53 \%$ of them were females and $86 \%$ were less than 25 years old. High school students consisted of $30.5 \%$, undergraduate university students $61 \%$, whereas postgraduate university students consisted of $8.5 \%$ of the participants.All the participants were using the internet to search for health information and $46.3 \%(\mathrm{n}=76)$ did that daily, $63.4 \%(\mathrm{n}=104)$ visited $1-5$ websites and $17.7 \%(\mathrm{n}=29)$ visited $6-10$ websites when they searched the internet for health information. More than three quarter(84.4\%) perceived internet health information as a help for improving their health status.Searching the internet health information for themselves was done by $22.6 \%(\mathrm{n}=37)$ and $73.2 \%(\mathrm{n}=120)$ searched for other persons including parents. Ninety four students $(57.3 \%)$ searched the internet for information on health and health care, physical fitness, nutrition and specific diseases. When the participants searched the internet for health information on a specific disease, $45.7 \%(n=75)$ of them looked for information on symptoms and $22.6 \%(n=37)$ sought information on medications. Half of the participants $(54.3 \%)$ found moderate benefit from the health information they got from the internet and $26.2 \%$ ( $\mathrm{n}=$ 43) reported a large benefit from it. Another half (54.9\%) stated that the health information they got from the internet generated new questions and $30.5 \%(n=50)$ reported that it stimulated a visit to their doctors. The detailed descriptive statistics of our study sample are shown in Table 1.

Table 1. General characteristics of study participants $(n=164)$

\begin{tabular}{|c|c|c|c|}
\hline \multirow{2}{*}{ Variables } & & \multicolumn{2}{|c|}{ Statistics } \\
\hline & & $N$ & $\%$ \\
\hline \multirow[t]{2}{*}{ Sex } & Male & 77 & 47 \\
\hline & Female & 87 & 53 \\
\hline \multirow{4}{*}{ Age } & $17-19$ & 48 & 29 \\
\hline & $20-22$ & 88 & 54 \\
\hline & $23-25$ & 5 & 3 \\
\hline & Above 25 & 23 & 14 \\
\hline \multirow{3}{*}{ Educational Level } & Secondary school students & 50 & 30.5 \\
\hline & Undergraduate university students & 100 & 61.0 \\
\hline & Postgraduate university students & 14 & 8.5 \\
\hline \multirow{4}{*}{$\begin{array}{l}\text { What is the number of different electronic sites } \\
\text { you entered searching for health information? }\end{array}$} & $1-5$ & 104 & 63.4 \\
\hline & $6-10$ & 29 & 17.7 \\
\hline & $11-15$ & 8 & 4.9 \\
\hline & 16 and more & 23 & 14.0 \\
\hline \multirow{4}{*}{$\begin{array}{l}\text { For whom did you search for health } \\
\text { information on the internet? }\end{array}$} & For myself & 37 & 22.6 \\
\hline & For one of my parents & 4 & 2.4 \\
\hline & For another person & 3 & 1.8 \\
\hline & All the above mentioned & 120 & 73.2 \\
\hline \multirow{5}{*}{$\begin{array}{l}\text { What is the type of health information you } \\
\text { searched for lately on the internet? }\end{array}$} & Health and health care & 12 & 7.3 \\
\hline & Physical fitness and nutrition & 28 & 17.1 \\
\hline & Specific diseases & 22 & 13.4 \\
\hline & All the above mentioned & 94 & 57.3 \\
\hline & Others & 8 & 4.9 \\
\hline \multirow{2}{*}{$\begin{array}{l}\text { When you search for health information on a } \\
\text { specific disease on the internet, what type of }\end{array}$} & Symptoms & 75 & 45.7 \\
\hline & Medications & 37 & 22.6 \\
\hline
\end{tabular}




\begin{tabular}{llrr}
\hline information do you search for? & Prognosis & 20 & 12.2 \\
\cline { 2 - 3 } & Others & 32 & 19.5 \\
\hline \multirow{3}{*}{$\begin{array}{l}\text { What was usually the effect of the health } \\
\text { information you got from the internet? }\end{array}$} & No effect & 4 & 2.4 \\
\cline { 2 - 3 } & Generated new questions & 90 & 54.9 \\
\cline { 2 - 3 } & Stimulated a visit to my doctor & 50 & 30.5 \\
\cline { 2 - 3 } & Stimulated a visit to another doctor than my doctor & 20 & 12.2 \\
\hline \multirow{2}{*}{$\begin{array}{l}\text { How do you evaluate your general health } \\
\text { condition? }\end{array}$} & (second opinion) & 15 & 9.1 \\
\cline { 2 - 3 } & Fair & 111 & 67.7 \\
\cline { 2 - 3 } & Good & 38 & 23.2 \\
\hline
\end{tabular}

We found $87.2 \%(n=143)$ of the participants trusted some of the internet's health information they retrieved, compared to nearly $10 \%$ who stated they trusted all internet health information. However, this had no statistical significance $(\mathrm{P}>0.05)$. Those who searched the internet health information to increase their knowledge equaled $65.9 \%(n=108)$ and $18.3 \%(n=30)$ searched it to check information before or after a visit to their doctors. Others $(15.9 \%)$, searched the internet as an alternative to visit their doctors, but this was without statistical significance $(\mathrm{P}>0.05)$.One hundred and thirty students $(79.3 \%)$ admitted that the health information they got from the internet affected their decision on health care or medical treatment and $76.2 \%(\mathrm{n}=125)$ reported that it affected their decisions on food choices or physical exercise. Again this was of no statistical significance $(P>0.05)$.

Table 2. Characteristics of Study Participants by Educational Level $(n=164)$

\begin{tabular}{|c|c|c|c|c|c|c|c|c|}
\hline \multirow{3}{*}{ Variables } & & \multicolumn{6}{|c|}{ Educational Level } & \multirow{3}{*}{$\begin{array}{c}\mathbf{p} \\
\text { value } \\
*\end{array}$} \\
\hline & & \multicolumn{2}{|c|}{ Secondary } & \multicolumn{2}{|c|}{ University } & \multicolumn{2}{|c|}{ Post-graduates } & \\
\hline & & $n$ & $\%$ & $n$ & $\%$ & $n$ & $\%$ & \\
\hline \multirow{3}{*}{$\begin{array}{l}\text { Trusting health } \\
\text { information from the } \\
\text { internet? }\end{array}$} & None & 3 & 60.0 & 1 & 20.0 & 1 & 20.0 & \multirow{3}{*}{0.244} \\
\hline & Some & 41 & 28.7 & 89 & 62.2 & 13 & 9.1 & \\
\hline & All & 6 & 37.5 & 10 & 62.5 & 0 & 0.0 & \\
\hline \multirow{4}{*}{$\begin{array}{l}\text { Reasons for searching } \\
\text { health information on } \\
\text { the internet? }\end{array}$} & $\begin{array}{l}\text { As alternative to visiting my } \\
\text { doctor }\end{array}$ & 7 & 26.9 & 18 & 69.2 & 1 & 3.8 & \multirow{4}{*}{0.961} \\
\hline & $\begin{array}{l}\text { Check information before } \\
\text { visiting the doctor }\end{array}$ & 6 & 31.6 & 11 & 57.9 & 2 & 10.5 & \\
\hline & $\begin{array}{l}\text { Check information after } \\
\text { visiting the doctor }\end{array}$ & 4 & 36.4 & 6 & 54.5 & 1 & 9.1 & \\
\hline & To increase my knowledge & 33 & 30.6 & 65 & 60.2 & 10 & 9.3 & \\
\hline \multirow{5}{*}{$\begin{array}{l}\text { Types of health } \\
\text { information searched } \\
\text { lately on the internet? }\end{array}$} & Health and health care & 2 & 16.7 & 9 & 75.5 & 1 & 8.3 & \multirow{5}{*}{0.656} \\
\hline & Physical fitness and nutrition & 6 & 21.4 & 20 & 71.4 & 2 & 7.1 & \\
\hline & Specific disease & 10 & 45.5 & 10 & 45.5 & 2 & 9.1 & \\
\hline & All the above mentioned & 29 & 30.9 & 56 & 59.6 & 9 & 9.6 & \\
\hline & Others & 3 & 37.5 & 5 & 62.5 & 0 & 0.0 & \\
\hline \multirow{2}{*}{$\begin{array}{l}\text { Have you ever talked } \\
\text { with your doctor about } \\
\text { the health information } \\
\text { you got from the } \\
\text { internet? }\end{array}$} & No & 28 & 40.0 & 40 & 57.1 & 2 & 2.9 & \multirow[b]{2}{*}{0.014} \\
\hline & Yes & 22 & 23.4 & 60 & 63.8 & 12 & 12.8 & \\
\hline
\end{tabular}




\begin{tabular}{|c|c|c|c|c|c|c|c|c|}
\hline $\begin{array}{l}\text { Internet health } \\
\text { information affects your } \\
\text { decisions concerning } \\
\text { health care or medical } \\
\text { treatment? }\end{array}$ & Yes & 10 & 29.4 & 20 & 58.8 & 4 & 11.8 & 0.751 \\
\hline $\begin{array}{l}\text { Health information you } \\
\text { got from the internet } \\
\text { affects your decisions } \\
\text { concerning food } \\
\text { choices or physical } \\
\text { exercises? }\end{array}$ & No & 15 & 38.5 & 20 & 51.3 & 10 & 10.3 & 0.364 \\
\hline $\begin{array}{l}\text { Health information got } \\
\text { from the internet } \\
\text { usually helps you in } \\
\text { improving your health? }\end{array}$ & No & 43 & 28.0 & 15 & 60.0 & 11 & 12.0 & 0.787 \\
\hline $\begin{array}{l}\text { The effect of the health } \\
\text { information you got } \\
\text { from the internet? }\end{array}$ & $\begin{array}{l}\text { No effect } \\
\text { Generated new questions } \\
\text { Stimulated a visit to my doctor } \\
\text { Stimulated a visit to another } \\
\text { doctor than my doctor (second } \\
\text { opinion) }\end{array}$ & $\begin{array}{c}1 \\
28 \\
18\end{array}$ & $\begin{array}{l}25.0 \\
31.1 \\
36.0\end{array}$ & $\begin{array}{l}2 \\
52 \\
29\end{array}$ & $\begin{array}{l}50.0 \\
57.8 \\
58.0\end{array}$ & $\begin{array}{c}1 \\
10 \\
3\end{array}$ & $\begin{array}{c}25.0 \\
11.1 \\
6.0\end{array}$ & 0.212 \\
\hline
\end{tabular}

*Based on the result of chi-squared test.

As shown in Table 2, students at higher educational levels talked significantly more often with their doctors regarding the health information they got from the internet $(\mathrm{P}=0.014)$.

In comparison, between students who perceived and who did not perceive improvement in health after using internet health information, we found that the participants who trusted the health information they got from the internet $(\mathrm{p}<0.001)$, who searched for internet information on health and health care, physical fitness and nutrition as well as on specific diseases $(p=0.005)$ and those who were stimulated by the internet health information to generate new questions or visit their doctors $(p=0.002)$ reported significantly higher rates of perception of internet information as a help for improving health. For more details on differences between students who perceived and who did not perceive improvement in health after using internet health information can be seen in Table 3 .

Table 3. The differences between students who perceived and who did not perceive improvement in health after using internet health information $(n=164)$

\begin{tabular}{|c|c|c|c|c|c|c|}
\hline \multirow{3}{*}{ Variables } & & \multicolumn{3}{|c|}{ Improvement in } & & \multirow{3}{*}{$\mathrm{p}$ value* } \\
\hline & & \multicolumn{2}{|c|}{ No } & & & \\
\hline & & $N$ & $\%$ & $n$ & $\%$ & \\
\hline \multirow{3}{*}{ Educational Level } & Secondary school students & 7 & 14.0 & 43 & 86.0 & \multirow{3}{*}{0.787} \\
\hline & Undergraduate university students & 15 & 15.0 & 85 & 85.5 & \\
\hline & Postgraduate university students & 3 & 21.4 & 11 & 78.6 & \\
\hline \multirow{5}{*}{$\begin{array}{l}\text { What is the type of health } \\
\text { information you searched for lately } \\
\text { on the internet? }\end{array}$} & Health and health care & 2 & 16.7 & 10 & 83.3 & \multirow{5}{*}{0.005} \\
\hline & Physical fitness and nutrition & 4 & 14.3 & 24 & 85.7 & \\
\hline & Specific disease & 3 & 13.6 & 19 & 86.4 & \\
\hline & All the above mentioned & 11 & 11.7 & 83 & 88.3 & \\
\hline & Others & 5 & 62.5 & 3 & 37.5 & \\
\hline
\end{tabular}




\begin{tabular}{|c|c|c|c|c|c|c|}
\hline \multirow{4}{*}{$\begin{array}{l}\text { When you search for health } \\
\text { information on a specific disease } \\
\text { on the internet, what type of } \\
\text { information do you search for? }\end{array}$} & Symptoms & 6 & 8.0 & 69 & 92.0 & \multirow{4}{*}{0.109} \\
\hline & Medications & 9 & 24.3 & 28 & 75.7 & \\
\hline & Prognosis & 4 & 20.0 & 16 & 80.0 & \\
\hline & Others & 6 & 18.8 & 26 & 81.2 & \\
\hline \multirow{4}{*}{$\begin{array}{l}\text { What is the number of different } \\
\text { websites you usually visit } \\
\text { searching for internet health } \\
\text { information? }\end{array}$} & $1-5$ & 19 & 18.3 & 85 & 81.7 & \multirow{4}{*}{0.394} \\
\hline & $6-10$ & 4 & 13.8 & 25 & 86.2 & \\
\hline & $11-15$ & 0 & 0.0 & 8 & 100.0 & \\
\hline & 16 and more & 2 & 8.7 & 21 & 91.3 & \\
\hline \multirow{4}{*}{$\begin{array}{l}\text { What was usually the effect of the } \\
\text { health information you got from } \\
\text { the internet? }\end{array}$} & No effect & 3 & 75.5 & 1 & 25.0 & \multirow{4}{*}{0.002} \\
\hline & Generated new questions & 16 & 17.8 & 74 & 82.2 & \\
\hline & Stimulated a visit to my doctor & 3 & 6.0 & 47 & 94.0 & \\
\hline & $\begin{array}{l}\text { Stimulated a visit to another doctor } \\
\text { than my doctor (second opinion) }\end{array}$ & 3 & 15.0 & 17 & 85.0 & \\
\hline \multirow{3}{*}{$\begin{array}{l}\text { How you evaluate your general } \\
\text { health condition? }\end{array}$} & Fair & 4 & 26.7 & 11 & 73.3 & \multirow{3}{*}{0.338} \\
\hline & $\overline{\text { Good }}$ & 17 & 15.3 & 94 & 84.7 & \\
\hline & Excellent & 4 & 10.5 & 34 & 89.5 & \\
\hline
\end{tabular}

*Based on the result of chi-squared test.

\section{Discussion}

More than $90 \%$ of our students searched the internet for health information. This represents a higher rate of internet use for health purposes than that found in studies on university students from USA (78\%) (Percheski \& Hargittai, 2011), Ghana (67.7\%) (OseiAsibey, 2017), Ireland (66.1\%) (Horgan \& Sweeney, 2012) and Saudi Arabia (50\%) (Albarak, 2016). Our study included students from different educational levels ranging from high school to post-graduate students. The vast majority of previous studies on use of internet as a health information source among students included under-graduate university students (Osei Asibey, Agyemang, \& Boakye Dankwah, 2017; Albarrak, 2016; O'Carroll, 2015; Aldebasi \& Ahmed, 2013; Horgan \& Sweeney, 2012; Mahmood et al., 2016; Percheski \& Hargittai, 2011). Educational level of students might play a central role on health information seeking behavior. Our study found no significant difference between students at different educational levels in use of internet as a source of health information, in its impact on the decisions concerning health care, medical treatment, food choices or physical exercises. However, we did find that students at higher educational levels talked significantly more often with their doctors about the health information they got from the internet $(\mathrm{P}=0.014)$. This might be explained by the fact that most school students are usually accompanied by their parents or caregivers during consultations with health professionals. In our study, $76.2 \%$ of the students used internet health information to assist them in improving their lifestyle through better food choices and higher rates of physical exercises. The study of Osei Asibey and colleagues from Ghana found a comparable rate $(72.4 \%)$ of use of internet heath information to modify the lifestyle of university students (Osei Asibey et al., 2017). However, a study among Saudi students found a lower rate of utilization of online health information on obesity to modify lifestyle (52.2\%) (Albarak, 2016). We found that $57.3 \%$ of our study sample discussed the health information they obtained from internet with their doctors. A study from Ghana observed a lower rate (39.5\%) of use of internet health information for discussions with health professionals (Osei Asibey et al., 2017). This may well be an indicator for the availability of less time for patient-physician interaction during clinic visits. More important is our finding that $84.4 \%$ of the students reported an improvement in their health after using health information from the internet. A lower rate of self-reported improvement in health after the use of internet health information was found by OseiAsibey and colleagues among Ghanaian students (73.6\%) (Osei Asibey et al., 2017).

\section{Conclusions and Recommendations}

The majority of our study participants used the internet as a source for health information and perceived the health information they received as a help for improving their health status. Interventions should be developed to enhance the use of internet health information among males and high school students. 


\section{Competing Interests Statement}

The authors declare that there are no competing or potential conflicts of interest.

\section{References}

Albarrak, A. I., Mohammed, R., Zakaria, N., Alyousef, L. M., Almefgai, N. B., Alqahtani, H. D., ... \& Alsulaiman, A. A. (2016). The impact of obesity related websites on decision making among students in Saudi Arabia. Saudi Pharmaceutical Journal, 24(5), 605-610. https://doi.org/10.1016/j.jsps.2015.03.016

Aldebasi, Y. H., \& Ahmed, M. I. (2013). Computer and Internet utilization among the medical students in Qassim University, Saudi Arabia. Journal of clinical and diagnostic research: JCDR, 7(6), 1105. https://doi.org/10.7860/JCDR/2013/5891.3092

Bakarman, M. A. (2017). Internet Addiction among Senior Medical Students in King Abdulaziz University, Prevalence and Association with Depression. Global Journal of Health Science, 9(10), 60-68.

Bensley, R. J., Hovis, A., Horton, K. D., Loyo, J. J., Bensley, K. M., Phillips, D., \& Desmangles, C. (2014). Accessibility and preferred use of online Web applications among WIC participants with Internet access. Journal of nutrition education and behavior, 46(3), S87-S92. https://doi.org/10.1016/j.jneb.2014.02.007

Britt, R. K., Collins, W. B., Wilson, K., Linnemeier, G., \& Englebert, A. M. (2017). eHealth literacy and health behaviors affecting modern college students: A pilot study of issues identified by the American College Health Association. Journal of medical Internet research, 19(12). https://doi.org/10.2196/jmir.3100

Gu, Y., Kalibatseva, Z., \& Song, X. (2017). Competencies for Effective Use of Online Depression Information Among College Students. Studies in health technology and informatics, 245, 1224-1224.

Horgan, Á., \& Sweeney, J. (2012). University students' online habits and their use of the Internet for health information. CIN: Computers, Informatics, Nursing, 30(8), 402-408. https://doi.org/10.1097/NXN.0b013e3182510703

Mahmood, S., Al Jeaidi, Z., Al-Onazi, M., Al-Shehri, A., \& Al-Harbi, A. (2016). A Cross-Sectional Analysis of Use of Information Technology by Selected Students of Health Colleges of a Saudi University. Journal of the College of Physicians and Surgeons--Pakistan: JCPSP, 26(6), 527-530.

O'Carroll, A. M., Westby, E. P., Dooley, J., \& Gordon, K. E. (2015). Information-seeking behaviors of medical students: A cross-sectional web-based survey. JMIR medical education, 1(1). https://doi.org/10.2196/mededu.4267

Osei Asibey, B., Agyemang, S., \& Boakye Dankwah, A. (2017). The internet use for health information seeking among Ghanaian university students: a cross-sectional study. International journal of telemedicine and applications, 2017. https://doi.org/10.1155/2017/1756473

Percheski, C., \& Hargittai, E. (2011). Health information-seeking in the digital age. Journal of American College Health, 59(5), 379-386. https://doi.org/10.1080/07448481.2010.513406

Power, J. M., Braun, K. L., \& Bersamin, A. (2017). Exploring the potential for technology-based nutrition education among WIC recipients in remote Alaska Native communities. Journal of nutrition education and behavior, 49(7), S186-S191. https://doi.org/10.1016/j.jneb.2016.11.003

Schwartz, J., \& Richardson, C. G. (2015). Exploring the potential for internet-based interventions for treatment of overweight and obesity in college students. Glob Health Promot, 22(4), 20-8. https://doi.org/10.1177/1757975914547546

Stellefson, M., Hanik, B., Chaney, B., Chaney, D., Tennant, B., \& Chavarria, E. A. (2011). eHealth literacy among college students: a systematic review with implications for eHealth education. Journal of medical Internet research, 13(4). https://doi.org/10.2196/jmir.1703

Stellefson, M., Hanik, B., Chaney, J. D., \& Tennant, B. (2012). Analysis of ehealth search perspectives among female college students in the health professions using Q methodology. Journal of medical Internet research, 14(2). https://doi.org/10.2196/jmir.1969

Tao, D., LeRouge, C., Smith, K. J., \& De Leo, G. (2017). Defining information quality into health websites: a conceptual framework of health website information quality for educated young adults. JMIR human factors, 4(4). https://doi.org/10.2196/humanfactors.6455 


\section{Copyrights}

Copyright for this article is retained by the author(s), with first publication rights granted to the journal.

This is an open-access article distributed under the terms and conditions of the Creative Commons Attribution license (http://creativecommons.org/licenses/by/4.0/). 